\title{
Preliminary study on the concentration of some heavy metals around a proposed cement factory in Kogi State Nigeria
}

\author{
E. OKORIE ${ }^{1 *}$, A. IBRAHIM ${ }^{1}$ and G. OKORIE ${ }^{2}$ \\ ${ }^{I}$ Department of Science Laboratory Technology, School of Technology, Federal Polytechnic Idah, \\ P.M.B. 1037 Idah, Kogi State, Nigeria. \\ ${ }^{2}$ Technical Department, pollution control/sanitation unit, National Environmental Standards and Regulations \\ Enforcement Agency, Oyo State Field office, OYSROMA House, opposite School of Hygiene, \\ Eleyele, P.M.B. 641, Ibadan, Oyo State, Nigeria. \\ *Corresponding author, E-mail: e.okorieslt@yahoo.com
}

\begin{abstract}
The analysis of soils from a cement mine site and the surrounding farmland for $\mathrm{Ni}, \mathrm{Pb}, \mathrm{Co}$ and $\mathrm{Cd}$ at different depths show concentrations that are generally below the maximum acceptable limits for land applications. Observed mean concentrations at the mine site are $0.3367 \mathrm{mg} / \mathrm{kg}, 0.1982 \mathrm{mg} / \mathrm{kg}$ and 0.1100 $\mathrm{mg} / \mathrm{kg}$ for $\mathrm{Ni}, \mathrm{Pb}$ and $\mathrm{Co}$ respectively. $\mathrm{Cd}$ was not detected. The observed mean concentrations in the surrounding farmland are $0.3800 \mathrm{mg} / \mathrm{kg}, 0.1705 \mathrm{mg} / \mathrm{kg}, 0.1143 \mathrm{mg} / \mathrm{kg}$ and $0.0064 \mathrm{mg} / \mathrm{kg}$ for Ni, $\mathrm{Pb}$, Co and Cd respectively. Thus the mine site land was not suspected to contributing to the heavy metal content in the agricultural land. The results obtained could act as a benchmark for future determinations on same study area when mining activities eventually commences.
\end{abstract}

(c) 2013 International Formulae Group. All rights reserved.

Keywords: FAAS, Heavy metals, cement, mine soil, agricultural land.

\section{INTRODUCTION}

Cement has been widely discovered to contain heavy metals. Its long term leachability is an important factor when assessing potential hazards. Elution of some of these metals like $\mathrm{Pb}, \mathrm{Cd}$, $\mathrm{Co}$ and $\mathrm{Ni}$ in different oxidation states has also become an environmental problem because cement contains trace amounts of these metals derived from raw materials such as iron slag and refractory bricks (Goluchowska and Strzyszcz, 1999). Previous reports on the concentration of heavy metals on farmlands around a mine site have been reported (Malgorzata and Marek, 2009; Waly et al., 2010; Begona et al., 1999). Industrial and mining waste waters are the major source of pollution by heavy metals. Heavy metals can pose health hazards if their concentrations exceed allowable limits. Even when the concentrations of metals do not exceed these limits, there is still a potential for long-term contamination, since heavy metals are known to be accumulated within biological systems. In recent years, increasing awareness of the environmental impact of heavy metals has prompted a demand for the purification of industrial waste prior to discharge into the natural environment (Mohammed et al., 1996). The environmental impacts of residues containing heavy metals produced by human activity are of increasing concern (Taylor and Crannell, 1997). The leaching of toxic chemicals from industrial sites onto aquatic environment presents a threat to sustaining water quality (Headley et al., 1993). Assuring 
safe disposal and long-term storage of hazardous wastes represents a primary environmental task of industrial societies. The long-term disposal of hazardous wastes is associated with landfilling of cementstabilized waste (Cho et al., 2005).

Several studies on the solubility of $\mathrm{Cd}$ and $\mathrm{Pb}$ in cement phases have been recorded with a small decrease in their lattice parameters (Prodjosantoso and Kennedy, 2003). Chromium, Cd and Co has also been found to be leached from cement ( $\mathrm{Yu}$ et al., 2005; Zhang et al., 2009; Bobrowski et al., 1997; Yang et al., 2009; Achternbosch et al., 2003). Some methods have been developed to stabilize some of these heavy metals in sewage sludge (Yi-Chin and Kung-Cheh, 2004; Wang et al., 2009; Quanyuan et al., 2009; Peysson et al., 2005; Juu-En et al., 1999; Paone, 2008; Vespa et al., 2006; Ahn et al., 2006; Liang et al., 2008).

The aim of this work is to investigate some trace element concentrations in the mine site and farmland around a proposed cement factory in Kogi State, Nigeria. The data obtained is intended to serve as reference for future soil determinations in the study area.

\section{MATERIALS AND METHODS}

Study area

The Obajana cement factory is located at Obajana (lat $7^{\circ} 54^{\prime} \mathrm{N}$ and $6^{\circ} 25^{\prime} \mathrm{E}$ ) north central Nigeria (Figure 1). The town is about 23.6 miles from lokoja the capital of Kogi State. It is a populated place with farming activities as the main source of income for the inhabitants. The factory is about two miles from the main town.

\section{Equipment}

The equipment used is the Pye Unicam 969 Flame Atomic Absorption Spectrophotometer equipped with hollowcathode lamps for $\mathrm{Pb}, \mathrm{Cd}, \mathrm{Co}$ and $\mathrm{Ni}$.

\section{Reagents used}

Deionized water, concentrated $\mathrm{HNO}_{3}$, concentrated $\mathrm{HCl}$. All reagents were of analytical reagent grade.

\section{Sampling/sample treatment}

Soil samples were collected in January through April 2006 from within and around the proposed cement mine site in Obajana, Kogi State. Five samples at different depths were collected from the mine site and subsequently at a nearby farmland. The sampling patterns ranged from topsoil to $20 \mathrm{~cm}$ depth. All the samples were air dried and pulverized using a pulverizing machine. The pulverized samples were stored in plastic containers.

\section{Procedure}

Analysis of $\mathrm{Pb}, \mathrm{Co}, \mathrm{Ni}$ and $\mathrm{Cd}$ was carried out by extracting the soil samples with aqua regia. $1 \mathrm{~g}$ of each of the finely ground samples was carefully weighed into $100 \mathrm{~cm}^{3}$ beaker using an electronic analytical balance. The samples were diluted with little amount of deionized water, and followed by the addition of $20 \mathrm{~mL}$ of concentrated $\mathrm{HCl}$. The mixture was placed on a hot plate and allowed to heat for 20 minutes after which $5 \mathrm{~mL}$ of concentrated $\mathrm{HNO}_{3}$ was added. The heating continued for 30 mins until dissolution is complete. The cooled samples were then filtered with Whatman No. 41 filter paper. The filtrate was made up to $100 \mathrm{~cm}^{3}$ with deionized water (Sutherland and Tack, 2002). This procedure was repeated for all the samples. The solutions were then analysed using Pye Unicam FAAS at the following operating wavelengths: $217.1 \mathrm{~nm}(\mathrm{~Pb}), 210.1$ $\mathrm{nm}(\mathrm{Co}), 228.9 \mathrm{~nm}(\mathrm{Cd})$ and $232.1 \mathrm{~nm}(\mathrm{Ni})$. To ensure reproducibility of the results, all the batch analysis were carried out in triplicates and the mean values are presented. Standard stock solutions of $\mathrm{Pb}, \mathrm{Ni}, \mathrm{Cd}$ and $\mathrm{Co}$ were prepared and calibrations recorded.

\section{Statistical analysis}

The statistical analysis of the results from mine site and farmland was carried out using paired sample t-test. The results of this analysis are shown in Tables 3, 4 and 5. 


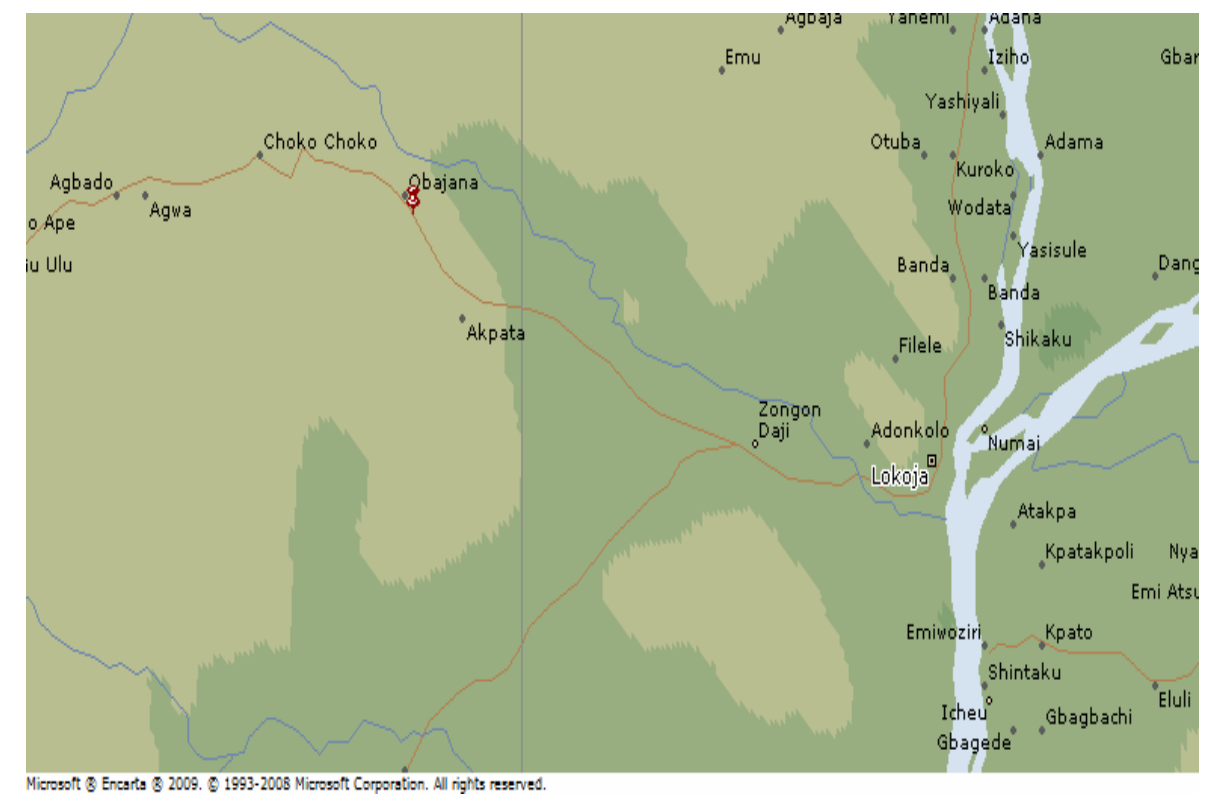

Figure 1: The study area.

\section{RESULTS AND DISCUSSION}

The results of the analysis of soil samples collected from the study area are presented in Tables 1 and 2 respectively.

The results of $\mathrm{Ni}$ analysis in both the mine site soil (Figure 2) and farmland around the mine site (Figure 3) show a higher concentration in the farmland than at the mine site. The $\mathrm{Ni}$ concentration at the mine site decreased from $0.3319 \pm 0.02 \mathrm{mg} / \mathrm{kg}$ (topsoil) to $0.3138 \pm 0.01 \mathrm{mg} / \mathrm{kg}$ (10 cm depth). A gradual increase was observed in $15 \mathrm{~cm}$ $(0.3432 \pm 0.03 \mathrm{mg} / \mathrm{kg})$ and $20 \mathrm{~cm}$ depths $(0.3643 \pm 0.03 \mathrm{mg} / \mathrm{kg})$. This decrease from topsoil to $10 \mathrm{~cm}$ depth and gradual increase from $15 \mathrm{~cm}$ to $20 \mathrm{~cm}$ depths may be attributed to the diffusion coefficients of $\mathrm{Ni}$ (Yang et al., 2009). The mean average of $\mathrm{Ni}$ concentration in the mine site is $0.3367 \mathrm{mg} / \mathrm{kg}$. This value however is far below the maximum acceptable limits for land use in industrial area (CCME).

The increase in the $\mathrm{Ni}$ concentration in the farmland from $0.3218 \pm 0.02 \mathrm{mg} / \mathrm{kg}$ (topsoil) to $0.5251 \pm 0.03 \mathrm{mg} / \mathrm{kg}(10 \mathrm{~cm})$ may be attributed to increased mobility of the metal and chemical speciation (Vespa et al., 2006). The mean of this determination is
$0.3800 \mathrm{mg} / \mathrm{kg}$ and far below the maximum acceptable limit for land application. However bioaccumulation may lead to deleterious effects on humans (Malgorzata and Marek, 2009). In $10 \mathrm{~cm}$ depth the observed concentration of $\mathrm{Pb}$ is $0.2235 \pm 0.01 \mathrm{mg} / \mathrm{kg}$. Thus $10 \mathrm{~cm}$ depth could be referred to as a zone of transition since there was a gradual increase in concentrations from this depth to $15 \mathrm{~cm}$. This followed a similar pattern for that of $\mathrm{Ni}$ analysis. This low value of $\mathrm{Pb}$ could be attributed to leaching (Prodjosantoso and Kennedy, 2003; Liang et al., 2008). The average concentration of $\mathrm{Pb}$ in the mine site is $0.1982 \mathrm{mg} / \mathrm{kg}$. On the other hand the concentration observed in the farmland for various depths are higher than in the mine site. The value decreased progressively from $0.2612 \pm 0.04 \mathrm{mg} / \mathrm{kg}$ (topsoil) to $0.0945 \pm 0.06$ $\mathrm{mg} / \mathrm{kg}$ (20 cm depth). Increased mobility of lead may plausibly be responsible for this progressive decline. Factors such as hydrological flow paths and the nature of the underlying soil matter may be a contributing factor to this decrease (Peysson et al., 2005). Cobalt concentration at the mine site ranged from $\quad 0.0764 \pm 0.06 \mathrm{mg} / \mathrm{kg}$ to $0.1215 \pm 0.01$ 


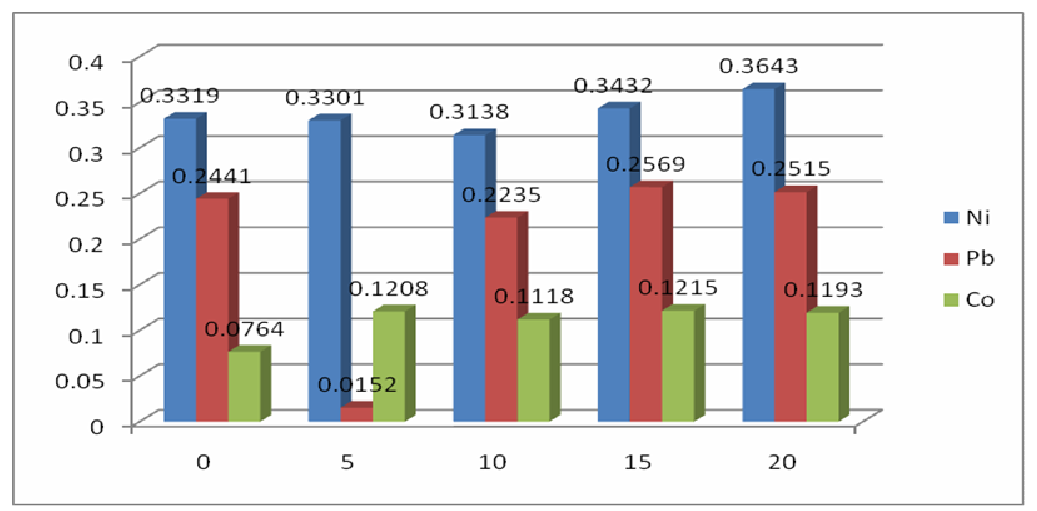

Figure 2: A bar chart of the concentration of the heavy metals as a function of soil depth in the mine site.



Figure 3: A bar chart showing the distribution of the heavy metals as function of soil depth in farmland around the mine site in Obajana, Kogi State.

Table 1: Results of soil analysis from Obajana mine site.

\begin{tabular}{lcccc}
\hline Sample depths $(\mathbf{c m})$ & \multicolumn{4}{c}{ Parameters $(\mathbf{m g} / \mathbf{k g})$} \\
\cline { 2 - 5 } & $\mathbf{N i}$ & $\mathbf{P b}$ & $\mathbf{C o}$ & $\mathbf{C d}$ \\
\hline Topsoil & $0.3319 \pm 0.02$ & $0.2441 \pm 0.04$ & $0.0764 \pm 0.06$ & $\mathrm{ND}$ \\
5 & $0.3301 \pm 0.01$ & $0.0152 \pm 0.01$ & $0.1208 \pm 0.02$ & $\mathrm{ND}$ \\
10 & $0.3138 \pm 0.01$ & $0.2235 \pm 0.01$ & $0.1118 \pm 0.03$ & $\mathrm{ND}$ \\
15 & $0.3432 \pm 0.03$ & $0.2569 \pm 0.02$ & $0.1215 \pm 0.01$ & $\mathrm{ND}$ \\
20 & $0.3643 \pm 0.03$ & $0.2515 \pm 0.03$ & $0.1193 \pm 0.01$ & $\mathrm{ND}$ \\
Mean & 0.3367 & 0.1982 & 0.1100 & ND \\
\hline Acceptable limits from & 50 & 600 & 300 & 22 \\
Canadian Council of Ministers & & & & \\
of Environment (CCME) & & & &
\end{tabular}


Table 2: Results of soil analysis from Obajana farmlands.

\begin{tabular}{lcccc}
\hline Sample depths (cm) & \multicolumn{4}{c}{ Parameters $(\mathbf{m g} / \mathbf{k g})$} \\
\cline { 2 - 5 } & $\mathbf{N i}$ & $\mathbf{P b}$ & $\mathbf{C o}$ & $\mathbf{C d}$ \\
\hline Topsoil & $0.3218 \pm 0.02$ & $0.2612 \pm 0.04$ & $0.1003 \pm 0.06$ & $0.0031 \pm 0.05$ \\
5 & $0.4142 \pm 0.01$ & $0.2518 \pm 0.02$ & $0.1081 \pm 0.04$ & $0.0028 \pm 0.04$ \\
10 & $0.5251 \pm 0.03$ & $0.1255 \pm 0.02$ & $0.1171 \pm 0.01$ & $\mathrm{ND}$ \\
15 & $0.2863 \pm 0.04$ & $0.1193 \pm 0.03$ & $0.1149 \pm 0.03$ & $\mathrm{ND}$ \\
20 & $0.3527 \pm 0.01$ & $0.0945 \pm 0.06$ & $0.1310 \pm 0.02$ & $0.0132 \pm 0.01$ \\
Mean & 0.3800 & 0.1705 & 0.1143 & 0.0064 \\
Acceptable limits (CCME) & 50 & 70 & 40 & 1.4 \\
\hline
\end{tabular}

$\mathrm{ND}=$ Not detected

Table 3: Paired Samples Statistics.

\begin{tabular}{llllll}
\hline & & Mean & N & Std. Deviation & Std. Error Mean \\
\hline Pair 1 & Mine site nickel & .336660 & 5 & .0186749 & .0083517 \\
& Farmland Nickel & .380020 & 5 & .0937228 & .0419141 \\
\hline Pair 2 & Mine site lead & .198240 & 5 & .1031049 & .0461099 \\
& Farmland lead & .170460 & 5 & .0794648 & .0355377 \\
\hline Pair 3 & Mine site cobalt & .109960 & 5 & .0191545 & .0085661 \\
& Farmland cobalt & .114280 & 5 & .0114185 & .0051065 \\
\hline Pair 4 & Mine site cadmium & .000000 & 5 & .0000000 & .0000000 \\
& Farmland cadmium & .003820 & 5 & .0054481 & .0024365 \\
\hline
\end{tabular}

Table 4: Paired Samples Correlations.

\begin{tabular}{lllcc}
\hline & & N & Correlation & Sig. \\
\hline Pair 1 & Mine site nickel \& Farmland Nickel & 5 & -.662 & .224 \\
Pair 2 & Mine site lead \& Farmland lead & 5 & -.577 & .308 \\
Pair 3 & Mine site cobalt \& Farmland cobalt & 5 & .652 & .233 \\
Pair 4 & Mine site cadmium \& Farmland cadmium & 5 &. &. \\
\hline \multicolumn{2}{l}{ The data for cadmium cannot be computed because at least one of the variables is constant. }
\end{tabular}


Table 5: Paired Samples Test.

\begin{tabular}{|c|c|c|c|c|c|c|c|c|c|}
\hline & & \multicolumn{5}{|c|}{ Paired Differences } & \multirow{3}{*}{$\mathbf{t}$} & \multirow{3}{*}{ df } & \multirow[b]{3}{*}{ Sig. (2-tailed } \\
\hline & & \multirow[b]{2}{*}{ Mean } & \multirow[b]{2}{*}{ Std. Deviation } & \multirow{2}{*}{$\begin{array}{c}\text { Std. Error } \\
\text { Mean }\end{array}$} & \multicolumn{2}{|c|}{$\begin{array}{l}\text { 99\% Confidence } \\
\text { Interval of the } \\
\text { Difference }\end{array}$} & & & \\
\hline & & & & & Lower & Upper & & & \\
\hline Pair 1 & Mine site nickel - Farmland Nickel & $-4.3360000 \mathrm{E}-2$ & .1069979 & .0478509 & -.2636702 & .1769502 & -.906 & 4 & .416 \\
\hline Pair 2 & Mine site lead - Farmland lead & $2.7780000 \mathrm{E}-2$ & .1624808 & .0726636 & -.3067703 & .3623303 & .382 & 4 & .722 \\
\hline Pair 3 & Mine site cobalt - Farmland cobalt & $-4.3200000 \mathrm{E}-3$ & .0145579 & .0065105 & -.0342949 & .0256549 & -.664 & 4 & .543 \\
\hline Pair 4 & Mine site cadmium - Farmland cadmium & $-3.8200000 \mathrm{E}-3$ & .0054481 & .0024365 & -.0150378 & .0073978 & -1.568 & 4 & .192 \\
\hline
\end{tabular}


$\mathrm{mg} / \mathrm{kg}$ with a mean of $0.1100 \mathrm{mg} / \mathrm{kg}$. For the farmland, the observed Co values ranged from $0.1003 \pm 0.06 \mathrm{mg} / \mathrm{kg}$ to $0.1310 \pm 0.02 \mathrm{mg} / \mathrm{kg}$ and a mean of $0.1143 \mathrm{mg} / \mathrm{kg}$. This high value in the farmland may be ascribed to the existence of $\mathrm{Co}$ in various oxidation states and its formation of hydroxides and immobilization in the soil matrix (Vespa et al., 2006).

Cadmium was not detected in the mine site while in the farmland; it was detected in the topsoil $(0.0031 \pm 0.05 \mathrm{mg} / \mathrm{kg}), 5 \mathrm{~cm}$ $(0.0028 \pm 0.04 \mathrm{mg} / \mathrm{kg})$ and $20 \mathrm{~cm}$ depths $(0.0132 \pm 0.01 \mathrm{mg} / \mathrm{kg})$. This variations in $\mathrm{Cd}$ concentration with depth may be due to its lattice parameters and immobilization to the soil matrix (Prodjosantoso and Kennedy, 2003; Yang et al., 2009; Yi-Chin and KungCheh, 2004).

\section{Student t-test}

From the statistical results Table 3 is the paired result of the paired samples statistics. The standard error of the mean ranged from $0.0024-0.046$. This is quite significant. Table 4 is a result of the paired samples correlations. Negative correlation was observed for mine site cobalt/farmland cobalt. The respective $\mathrm{p}$-values are all above 0.05 and are therefore not significant. The paired samples test as shown in Table 5 indicates a tvalue of -0.906 and a p-value of 0.416 for mine site nickel/farmland nickel. Thus there is no significance between mine site nickel and farmland nickel. This trend was also observed in mine site cadmium/farmland cadmium where the $t$-value is -1.568 and a $p$-value of $0.192(>0.05)$.

However, the mine site lead/farmland lead showed a p-value of 0.722 and a t-value of 0.382. The p-value for mine site cobalt/farmland cobalt is $0.543(>0.05)$. This does not show any significant difference in the studied samples.

\section{Conclusion}

From an environmental point of view, the metals analyzed were all far below the maximum acceptable limits for both agricultural and industrial land applications.
However, bioaccumulation may result in the objectionable increase in these metals on plants. The mine site land is not suspected to contribute to the enrichment of these metals in the farmland soil as the observed concentrations show a natural concentration on both soils.

\section{REFERENCES}

Achternbosch M, Bräutigam RK, Gleis M, Hartlieb N, Kupsch C, Richers U. 2003. Heavy metals in cement and concrete resulting from the co-incineration of wastes in cement Kilns with regard to the legitimacy of waste utilization. Wissenschaftliche Berichte FZKA, 6923: 1-187.

Ahn JW, You KS, Han GC, Cho KH. 2006. Stabilization behaviour of heavy metals derived from wastes on cementitious minerals and hydrates. Mat. Sci. Forum, 510-511: 630-633.

Begona V, Riansares M, Andres I, Luquede Castro MD. 1999. Cement for stabilization of industrial residues containing heavy metals. J. Environ. Monit., 1: 563-568.

Bobrowski A, Gawlicki M, Malolepszy J. 1997. Analytical evaluation of immobilization of heavy metals in cement matrices. Environ. Sci. Technol., 31(3): 745-749.

CCME (Canadian Council of Ministers of the Environment). 1997. Interim Canadian environmental quality criteria for contaminated sites. CCME Winipeg.

Cho H, Oh D, Kim K. 2005. A study on removal characteristics of heavy metals from aqueous solution by fly ash. $J$. hazard. Mater., 127: 187-195.

Goluchowska B, Strzyszcz Z. 1999. Ecol. Chem. Eng., 6(2-3): 217-227.

Headley JV, Brooks PW, Neuwirth M. 1993. Contaminant interactions at surfaces for treatment of heavy metals in aquatic environments - mass spectrometry studies. Proc. of the Rostov-on-Don Symposium on Hydrological, Chemical and Biological processes of 
transformation and Transport of contaminants in Aquatic Environments. IAHS Publ. N 219, 1994; 75-79.

Juu-En C, Tzong-Tzeng L, Ming-Sheng K, Der-Shyun L. 1999. Stabilization/ solidification of sludges containing heavy metals by using cement and waste pozzolans. J. Environ. Sci. Health, Part A, 34(5): 1143-1160.

Liang S, Jiang J, Zhang Y, Xu X. 2008. Leaching characteristics of heavy metals during cement stabilization of fly ash from municipal solid waste incinerators. Front. Environ. Sci. Engin. China, 2(3): 358-363.

Ma J, Wang J, Zhao Y, Liu T, Wang L. 2009. Stabilization of heavy metals in sewage sludge using Sorel cement. Proc. of the International Conference on Chemical, Biological and Environmental Engineering; 69-75.

Malgorzata AJ, Marek J. 2009. Influence of cement industry on accumulation of heavy metals in bioindicators. Ecol. Chem. Eng. S, 16(3): 323-334.

Mohammed A, Rafaqat AKR, Bilquees AS. 1996. Studies on the removal and recovery of $\mathrm{Cr}$ (IV) from electroplating waste. Water Res., 30(3): 1478-1482.

Paone P. 2008. Heavy metals in the cement industry: A look at volatile cycles and simple mitigation techniques. Proc. Cement Industry Technical Conference Record, IEEE, 65-75.

Peysson S, Pera J, Chabannet M. 2005. Immobilization of heavy metals by calcium sulfoaluminate cement. Cement Concrete Res., 35(12): 2261-2270.

Prodjosantoso AK, Kennedy BJ. 2003. Heavy metals in cement phases: on the solubility of $\mathrm{Mg}, \mathrm{Cd}, \mathrm{Pb}$ and $\mathrm{Ba}$ in $\mathrm{Ca}_{3} \mathrm{Al}_{2} \mathrm{O}_{6}$. Cement Concrete Res., 33(7): 1077-1084.

Quanyuan C, Mark J, Hills CD, Yang XM, Carey PJ. 2009. Immobilization of heavy metals in cement-based solidification/stabilization; a review. Waste Mgmt, . 29(1): 390-403.

Sutherland RA, Tack FMG. 2002. Determination of $\mathrm{Al}, \mathrm{Cu}, \mathrm{Fe}, \mathrm{Mn}, \mathrm{Pb}$ and $\mathrm{Zn}$ in certified reference materials using the optimized BCR sequential extraction procedure. Analytica Chimica Acta, 454(2): 249.

Taylor T, Crannell BS. 1997. Environ. Sci. Technol., 31: 3330.

Vespa M, Dahn R, Grolimund D, Harfouche M, Wieland E, Scheidegger AM. 2006. Speciation of heavy metals in cementstabilised waste forms: A microspectroscopic study. J. Geochem. Exploration, 88(1-3): 77-80.

Waly TA, Dakroury AM, El-Sayed GO, ElSalam SA. 2010. Assessment removal of heavy metals ion from wastewater by cement Kiln dust (CKD). J. Am. Sci., 6(12): 910-917.

Yang YF, Huang QF, Zhang X, Yang Y, Wang Q. 2009. Release amount of heavy metals in cement product from coprocessing waste in cement Kiln. Huan Jing Ke Xue, 30(5): 1539-1544.

Yi-Chin H, Kung-Cheh L. 2004. Monitoring the tendency of heavy metals leached from cement mortar. Pract. Periodical of Haz., Toxic, and Radioactive Waste Mgmt., 8(1): 26-30.

Yu Q, Nagataku S, Lin J, Saeki T, Hisada M. 2005. The leachability of heavy metals in hardened fly ash cement and cementsolidified fly ash. Cement Concrete Res., 33(7): 1056-1063.

Zhang J, Liu J, Li C, Jin Y, Nie Y, Li J. 2009. Comparison of the fixation effects of heavy metals by cement rotary Kiln coprocessing and cement based solidification/stabilization. J. hazard. Mater., 165(1-3): 1179-1185. 